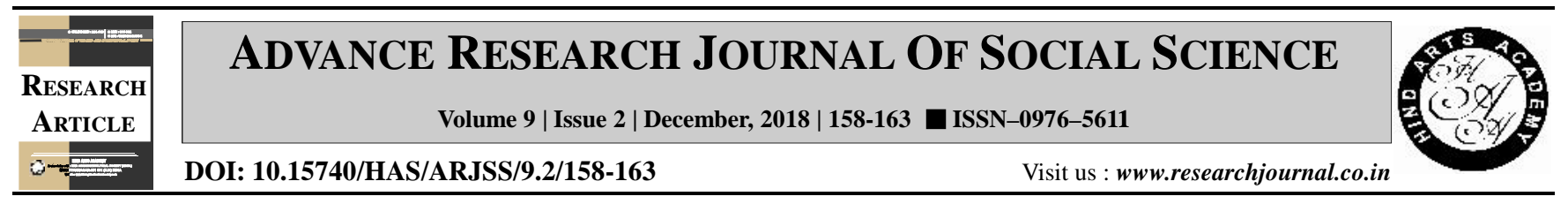

\title{
Socio-economic profile of onion growers in north Karnataka
}

Vaishnavi Sangam and S.G. Aski*

Department of Agricultural Extension Education, College of Agriculture, Vijayapura (Karnataka) India Email : askisubhash@gmail.com

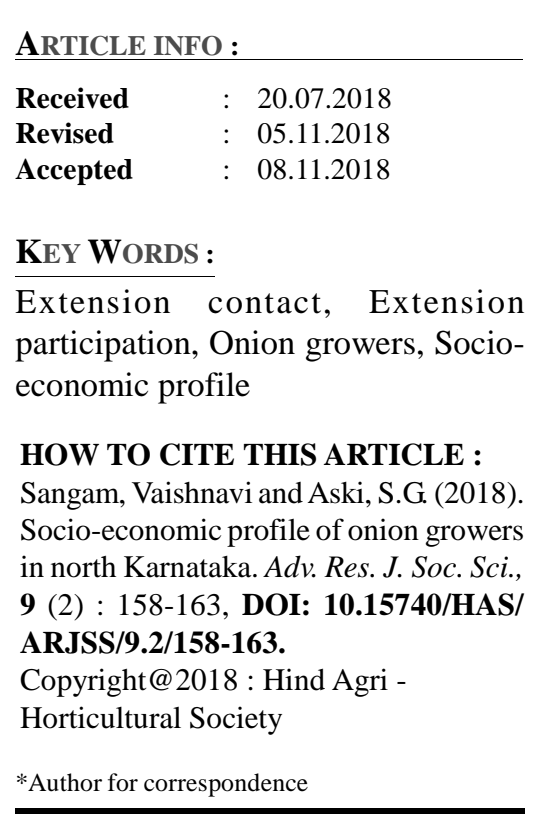
\begin{abstract}
Socio-economic status is an economic and sociological combined measure of a person's work experience and of an individual's or family's economic and social position in relation to others. The study was conducted in Vijayapur district of Karnataka, collecting data from 150 onion growers during 2017-18. Nearly half (52.67\%) of the respondents belonged to middle age category, More number $(25.33 \%)$ of the respondents were educated upto primary school. Majority (63.34\%) of the respondents had an annual income of more than Rs. 51,000, nearly half (54.67\%) of the respondents belonged to nuclear family type category. About 28.67 per cent of the respondents belonged to medium land holding category, majority $(61.34 \%)$ of the respondents had farming experience of more than 17 years, 43.33 per cent of the respondents belonged to low extension contact category. Nearly half (47.33\%) of respondents had medium extension participation, 44.00 per cent of the respondents belonged to medium mass media exposure category. More than half of the respondents had medium social participation $(52.67 \%)$, medium decision making ability $(68.00 \%)$, medium innovativeness (59.33\%) and 42.67 per cent of the respondents belonged to medium cosmopoliteness category.
\end{abstract}

